\title{
Correlates of body mass index (BMI) with their socio- economic status of urban and rural adults of Varanasi district
}

PRIYANKA AND ARCHANA CHAKRAVARTY

Received: 08.01.2015; Revised: 03.04.2015; Accepted: 18.04.2015

See end of the paper for authors' affiliations

\section{PRIYANKA}

Department of Home Science, Mahila Mahavidyalaya (B.H.U.), VARANASI (U.P.) INDIA

Email : pritu.priyanka@gmail.com
ABSTRACT : Nutritional status the condition of health of an individual and it can be evaluated in many ways, but BMI is the most established anthropometric indicator used for assessment of adult nutritional status. Objectives of the present study are to assess the nutritional status (BMI) of urban and rural adults of Varanasi district and to determine the association between BMI and socio-economic status. A community based crossectional study was undertaken on 304 adults (Urban 152, Rural 152), 18-60 years of age group. A pre-tested and pre-designed questionnaire was used to collect the information for the study. Socio-economic and demographic information of study subject was assessed by interview technique. BMI was calculated using the formula [weight $(\mathrm{kg}) /$ height $(\mathrm{mt})^{2}$ ]. Both the community was the hindu dominant out of which majority of proportion are GEN caste. Rural subjects have significantly low educational status and low socio-economic status as compare to urban subjects. The proportions of rural males were significantly more than the urban males in case of doing heavy work. There was no significant difference in average BMI, between urban and rural areas of male as well as female subjects. Only 11.1 per cent and 9.8 per cent of urban and rural males and 25.8 per cent and 30.8 per cent of urban and rural females are in underweight category of BMI. There is no significant difference in average BMI of male as well as female subjects between urban and rural locality with reference to their various socio-economic and demographic variables with the exception of high socio-economic status, among male subjects, among heavy type of work, among low and medium socio-economic status in females, respectively.

KEY WORDS: Adults, Nutritional status, Body mass index, Urban, Rural, Socio-economic status

- HOW TO CITE THIS PAPER : Priyanka and Chakravarty, Archana (2015). Correlates of body mass index (BMI) with their socio-economic status of urban and rural adults of Varanasi district. Asian J. Home Sci., 10 (1) : 108-115. 